\title{
Nitrogênio e enxofre em características produtivas do capim-braquiária proveniente de área de pastagem em degradação ${ }^{1}$
}

\author{
Edna Maria Bonfim-Silva², Francisco Antonio Monteiro ${ }^{3}$ \\ ${ }^{1}$ Parte da tese de Doutorado da primeira autora apresentada à Escola Superior de Agricultura "Luiz de Queiroz" - ESALQ/USP. Projeto \\ apoiado pela FAPESP \\ 2 Pós-doutoranda, Departamento de Solos e Nutrição de Plantas. Bolsista do CNPq. \\ ${ }^{3}$ Departamento de Solos e Nutrição de Plantas, C. Postal 9, Piracicaba, SP. Bolsista do CNPq.
}

\begin{abstract}
RESUMO - Objetivou-se avaliar os efeitos de combinações de doses de $\mathrm{N}$ com as de $\mathrm{S}$ para as características produtivas do capim-braquiária (Brachiaria decumbens), coletado em cilindros com plantas + solo em uma pastagem em degradação em área de Neossolo Quartzarênico. O experimento foi conduzido em casa-de-vegetação, no período de novembro de 2003 a março de 2004. Foram utilizadas cinco doses de $\mathrm{N}\left(0 ; 100 ; 200 ; 300\right.$ e $\left.400 \mathrm{mg} / \mathrm{dm}^{3}\right)$ e cinco doses de $\mathrm{S}\left(0 ; 10 ; 20 ; 30\right.$ e $\left.40 \mathrm{mg} / \mathrm{dm}^{3}\right)$, combinadas em estudo de superfície de resposta baseado em desenho experimental composto central modificado de um fatorial $5^{2}$ fracionado. Realizaram-se três cortes nas plantas, em intervalos de 30 dias. As doses de $\mathrm{N}$ e de $\mathrm{S}$ foram determinantes para o número de perfilhos, produção de massa seca das lâminas foliares e dos colmos mais bainhas no primeiro crescimento da gramínea e para a relação folha:colmo no segundo crescimento. A adubação com $\mathrm{N}$ teve efeito isolado no número de perfilhos e na produção de massa seca das lâminas foliares e dos colmos mais bainhas no segundo e no terceiro crescimentos. O número de folhas foi influenciado pelas doses de $\mathrm{N}$ e de $\mathrm{S}$ de forma isolada, no primeiro crescimento, e pelas doses de $\mathrm{N}$ no segundo e no terceiro crescimentos. As relações entre as doses de $\mathrm{N}$ e as de $\mathrm{S}$ para obtenção das máximas produções de massa seca foram, de maneira geral, em torno de 10:1. A aplicação, principalmente de $\mathrm{N}$ mas também de $\mathrm{S}$, influenciou as características produtivas do capim-braquiária e conseqüentemente a sua recuperação.
\end{abstract}

Palavras-chave: Brachiaria decumbens, folhas, perfilhos, relação folha:colmo

\section{Nitrogen and sulphur for productive characteristics of signalgrass from degrading pasture area}

\begin{abstract}
The objective of this work was to evaluate the effects of combined rates of $\mathrm{N}$ and $\mathrm{S}$ on signalgrass (Brachiaria decumbens) productive characteristics. This grass was collected in cylinders with soil + plants in a degrading pasture established in an Entisol. The experiment was carried out in a greenhouse, at Piracicaba, SP, Brazil, from November 2003 to March 2004 Five rates of $\mathrm{N}\left(0,100,200,300\right.$ and $\left.400 \mathrm{mg} / \mathrm{dm}^{3}\right)$ were combined with five rates of $\mathrm{S}\left(0,10,20,30\right.$, and $\left.40 \mathrm{mg} / \mathrm{dm}^{3}\right)$ in a fractionated $5^{2}$ factorial, based on a central composite design. Plants were harvested following three periods of 30 days growth. The combination between $\mathrm{N}$ and $\mathrm{S}$ rates affected the number of tillers, dry matter yield of leaf blade and stems plus sheaths at the first harvest and the leaf blade: stems plus sheaths ratio at the second harvest. Nitrogen rates had effects on the number of tillers and on dry matter yield of leaf blade and stems plus sheaths at the second and third harvests. At the first growth, the leaf number of the grass was changed by both $\mathrm{N}$ and $\mathrm{S}$ rates, and by $\mathrm{N}$ rates at the second and third growths. Maximum dry matter yields were reached when $\mathrm{N}$ and $\mathrm{S}$ rates were applied at about 10:1 ratio. The application of mainly $\mathrm{N}$, but also of $\mathrm{S}$, affected the productive characteristics of signalgrass, and its recovery.
\end{abstract}

Key Words: Brachiaria decumbens, leaves, leaf:stem ratio, tillers

\section{Introdução}

Os solos de melhor aptidão agrícola normalmente são ocupados pelas lavouras anuais de grãos ou pelas de grande valor industrial, para a produção de óleo, fibras, açúcar e outros (Macedo, 1999), enquanto os ocupados por pastagens são, geralmente, mais pobres em termos de fertilidade do solo e condições físicas.
A partir dos anos 70, as gramíneas do gênero Brachiaria Griseb. têm aumentado sua participação nas pastagens brasileiras, sendo utilizadas em substituição a outras espécies, em processo que foi liderado pelo capimbraquiária (Brachiaria decumbens Stapf). Estima-se que as braquiárias ocupem em torno de 95 milhões de hectares no país e 7,6 milhões de hectares somente no estado de São Paulo (Ferreira et al., 1999), com apreciável área estando 
pelo menos em processo de degradação. Assim, torna-se necessário buscar modo de recuperação dessas pastagens e, nesse contexto, a adubação enquadra-se como uma necessidade.

A adubação tem sido indispensável na formação, na manutenção e na recuperação das pastagens e, de modo particular, a adubação nitrogenada tem sido uma das maiores necessidades nos casos de pastagens exclusivas de gramíneas, quando se trata da recuperação de áreas degradadas. Desse modo, todos os nutrientes das plantas podem ser limitantes em determinada condição de pastagem, mas tem sido freqüente a limitação por $\mathrm{N}$ e S (Myers \& Robbins, 1991; Soares Filho, 1993).

Partindo-se da hipótese que determinadas combinações de N e S na adubação são apropriadas para influenciar as características produtivas do capim-braquiária, a ponto de resultar em adequada recuperação da pastagem em degradação, objetivou-se neste trabalho determinar a influência das combinações desses nutrientes nas características produtivas do capim-braquiária em recuperação, como: número de perfilhos e de folhas, massa seca das lâminas foliares e dos colmos mais bainhas e relação folha:colmo.

\section{Material e Métodos}

O experimento foi conduzido em casa-de-vegetação, em Piracicaba-SP, no período de novembro de 2003 a março de 2004. Optou-se por realizar esse estudo em condições controladas, em vista da possibilidade de estudar uma série de combinações entre as doses de cada nutriente, de evitar a interferência de nutrientes extra-adubação no fornecimento desses dois nutrientes e garantir adequações de fornecimento de água e de temperatura ambiente para o normal desenvolvimento das plantas.

Coletaram-se amostras de capim-braquiária + solo em cilindros de $15 \mathrm{~cm}$ de diâmetro e $20 \mathrm{~cm}$ de profundidade numa pastagem em estádio de degradação, em Neossolo Quartzarênico na Fazenda Agrícola Brejo das Almas, no município de Santa Maria da Serra, SP. Essas amostras de solo junto com plantas foram colocadas em vasos plásticos, conforme técnica descrita por Mattos \& Monteiro (2003).

As características químicas da amostra superficial $(0-20 \mathrm{~cm})$ do solo coletado na área de pastagem em degradação, antes da aplicação dos tratamentos, foram: $\mathrm{pH}\left(\mathrm{CaCl}_{2}\right)$ $=5,43 ;$ M.O. e N-total $=28$ e $1,75 \mathrm{~g} / \mathrm{kg}$, respectivamente; $\mathrm{N}-\mathrm{NH}_{4}{ }^{+}$e $\mathrm{N}^{-\mathrm{NO}_{3}}{ }^{-}=8,40$ e $2,80 \mathrm{mg} / \mathrm{kg}$, respectivamente; P-resina e S-sulfato $=4,03$ e 4,32 $\mathrm{mg} / \mathrm{dm}^{3}$, respectivamente; S-total $=150 \mathrm{~g} / \mathrm{kg} ; \mathrm{K} ; \mathrm{Ca} ; \mathrm{Mg} ; \mathrm{H}+\mathrm{Al} ; \mathrm{SB}$ e CTC $=2,28 ; 14,60$; 10,$40 ; 28,20 ; 27,28$ e $55,48 \mathrm{mmol}_{\mathrm{c}} / \mathrm{dm}^{3}$, respectivamente; $\mathrm{Ve}$ $\mathrm{m}=49,17$ e $11,83 \%$, respectivamente.
Durante 30 dias, as plantas foram adaptadas ao novo ambiente. Os vasos puderam compor blocos uniformes e foram distribuídos segundo o delineamento experimental de blocos ao acaso, com quatro repetições. Realizou-se um corte de uniformização das plantas a $5 \mathrm{~cm}$ do colo das plantas e foram aplicados os tratamentos.

Foram utilizadas cinco doses de N $(0 ; 100 ; 200 ; 300$ e 400 $\left.\mathrm{mg} / \mathrm{dm}^{3}\right)$ e cinco de $\mathrm{S}\left(0 ; 10 ; 20 ; 30\right.$ e $\left.40 \mathrm{mg} / \mathrm{dm}^{3}\right)$, as quais foram combinadas em estudo de superfície de resposta com base em desenho experimental composto central modificado de um fatorial $5^{2}$ fracionado, de acordo com Littell \& Mott (1975). Assim, empregaram-se 13 combinações de $\mathrm{N}$ com S $\left(\mathrm{em} \mathrm{mg} / \mathrm{dm}^{3}\right): 0,0 ; 0,20 ; 0,40 ; 100,10 ; 100,30 ; 200,0 ; 200$, $20 ; 200,40 ; 300,10 ; 300,30 ; 400,0 ; 400,20$ e 400,40 . O N foi fornecido como nitrato de amônio $\left(\mathrm{NH}_{4} \mathrm{NO}_{3}\right)$ e o S como sulfato de cálcio $\left(\mathrm{CaSO}_{4} \cdot 2 \mathrm{H}_{2} \mathrm{O}\right)$, sendo a quantidade de cálcio $(\mathrm{Ca})$ equilibrada em todas as parcelas experimentais pelo emprego de cloreto de cálcio $\left(\mathrm{CaCl}_{2}\right)$. Após o corte de uniformização das plantas foram aplicados: fósforo ( $\mathrm{P}$ como $\mathrm{CaH}_{2} \mathrm{PO}_{4}$ e $\mathrm{KH}_{2} \mathrm{PO}_{4}$ ) de $200 \mathrm{mg} / \mathrm{dm}^{3}$, potássio ( $\mathrm{K}$ como $\mathrm{KH}_{2} \mathrm{PO}_{4}$ e $\mathrm{KCl}$ ) de $150 \mathrm{mg} / \mathrm{dm}^{3}$ e magnésio $(\mathrm{Mg}$ como $\mathrm{MgCl}_{2} \cdot 6 \mathrm{H}_{2} \mathrm{O}$ ) de $50 \mathrm{mg} / \mathrm{dm}^{3}$. As adubações com N, S e K foram repetidas após cada corte realizado, enquanto a adubação com $\mathrm{Mg}$ foi modificada para $20 \mathrm{mg} / \mathrm{dm}^{3}$ devido à não-aplicação de $\mathrm{P}$ (que levava junto o $\mathrm{Ca}$ ) a partir do primeiro corte das plantas e, em conseqüência, da diminuição no fornecimento de Ca. A adubação básica com os micronutrientes foi efetuada com $\mathrm{H}_{3} \mathrm{BO}_{3}$ de $1,5 \mathrm{mg} / \mathrm{dm}^{3}$, $\mathrm{CuCl}_{2} \cdot 2 \mathrm{H}_{2} \mathrm{O}$ de $2,5 \mathrm{mg} / \mathrm{dm}^{3}, \mathrm{ZnCl}_{2}$ de $2,0 \mathrm{mg} / \mathrm{dm}^{3}$ e de $\mathrm{Na}_{2} \mathrm{MoO}_{4} \cdot 2 \mathrm{H}_{2} \mathrm{O}$ de $0,25 \mathrm{mg} / \mathrm{dm}^{3}$, realizada apenas após o corte de uniformização das plantas. As adubações com macronutrientes foram estabelecidas em função da análise de solo e as adubações com micronutrientes adaptadas de Mattos \& Monteiro (2003).

A umidade dos vasos foi mantida por meio de um sistema autoirrigante, por tensão controlada, composto por cápsula de porcelana porosa, adaptado de Bonfim-Silva (2002). Foram realizados três cortes na parte aérea das plantas, a intervalos regulares de 30 dias de crescimento. A altura do corte foi de $5 \mathrm{~cm}$ do colo das plantas para o primeiro e segundo cortes e rente ao colo das plantas no terceiro corte. O número total de perfilhos e de folhas verdes expandidas foi determinado por ocasião dos cortes das plantas. Em cada um dos cortes, procedeu-se à separação da parte aérea em lâminas foliares e colmos mais bainhas. As frações da parte aérea foram acondicionadas em sacos de papel e secas em estufa a $65^{\circ} \mathrm{C}$ até massa constante. Para determinação da relação folha:colmo, dividiu-se a massa seca das lâminas foliares pela massa seca dos colmos mais bainhas. 
A temperatura média do período experimental foi de $30^{\circ} \mathrm{C}$, com anotação da temperatura iniciada na aplicação dos tratamentos.

Todos os resultados receberam o tratamento estatístico com análise em superfície de resposta, utilizando-se o programa Statistical Analysis System (SAS, 1996). Inicialmente, foi realizada a análise de variância para as combinações das doses de $\mathrm{Ne} \mathrm{S}$ e, em função do nível de significância do teste $\mathrm{F}$, efetuou-se o estudo de regressão polinomial (superfície de resposta) por meio do procedimento RSREG. Nos casos em que a interação doses de $\mathrm{N} \times$ doses de $\mathrm{S}$ não foi significativa, efetuou-se o estudo de regressão de primeiro e segundo graus, por meio do comando GLM. Utilizou-se o nível de significância de $5 \%$ em todos os testes estatísticos.

No estudo de regressão polinomial(superfície de resposta), as doses de $\mathrm{N}$ e $\mathrm{S}$ responsáveis pelas máximas produções foram fornecidas pela saída de resultados ("output") do programa SAS. Para os casos de significância de regressão de segundo grau, as doses de $\mathrm{N}$ ou S responsáveis pelos máximos valores foram obtidas por meio de derivada.

\section{Resultados e Discussão}

O número de perfilhos do capim-braquiária apresentou comportamento diferenciado do primeiro para o segundo e terceiro crescimentos. A interação doses de $\mathrm{N} \times$ doses de $\mathrm{S}$ foi significativa para o número total de perfilhos por ocasião do primeiro crescimento, ajustando-se ao modelo polinomial de regressão. No entanto, para o segundo e terceiro crescimentos foi verificada significância apenas para as doses de $\mathrm{N}$, com os resultados ajustando-se ao modelo quadrático de regressão. No primeiro crescimento, por meio do estudo de superfície de resposta, constatou-se que a dose de $\mathrm{N}$ de $416 \mathrm{mg} / \mathrm{dm}^{3}$ associada à dose de $\mathrm{S}$ de 35 $\mathrm{mg} / \mathrm{dm}^{3}$ (relação de 12:1) proporcionaria o máximo número de perfilhos e, portanto, a dose de $\mathrm{N}$ para a máxima produção de perfilhos excedeu as doses do intervalo experimental (Figura 1A).

Rodrigues (2002) verificou interação significativa doses de $\mathrm{N} \times$ doses de $\mathrm{S}$, no segundo período de crescimento do capim-braquiária, para o número de perfilhos, demonstrando que, quando se utilizam elevadas doses de $\mathrm{N}$, é necessária mais elevada dose de $\mathrm{S}$ para que a gramínea alcance maior perfilhamento. No segundo crescimento do capim-braquiária, a dose de $\mathrm{N}$ de $325 \mathrm{mg} / \mathrm{dm}^{3}$ foi responsável pelo máximo perfilhamento (Figura 1B). No entanto, no terceiro crescimento a dose de $\mathrm{N}$ que proporcionou a máxima produção de perfilhos foi de $297 \mathrm{mg} / \mathrm{dm}^{3}$ (Figura 1C).

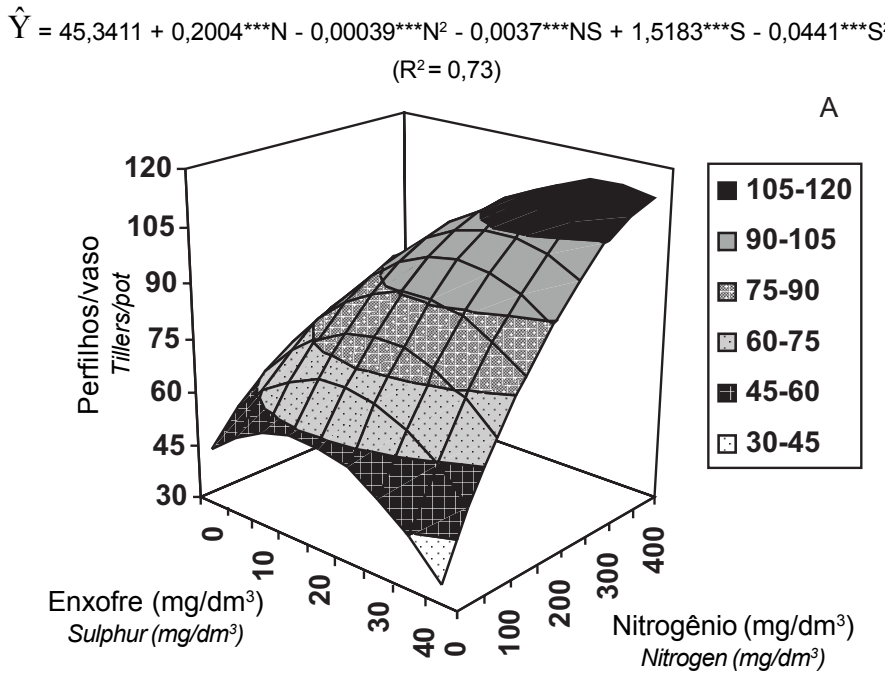

B
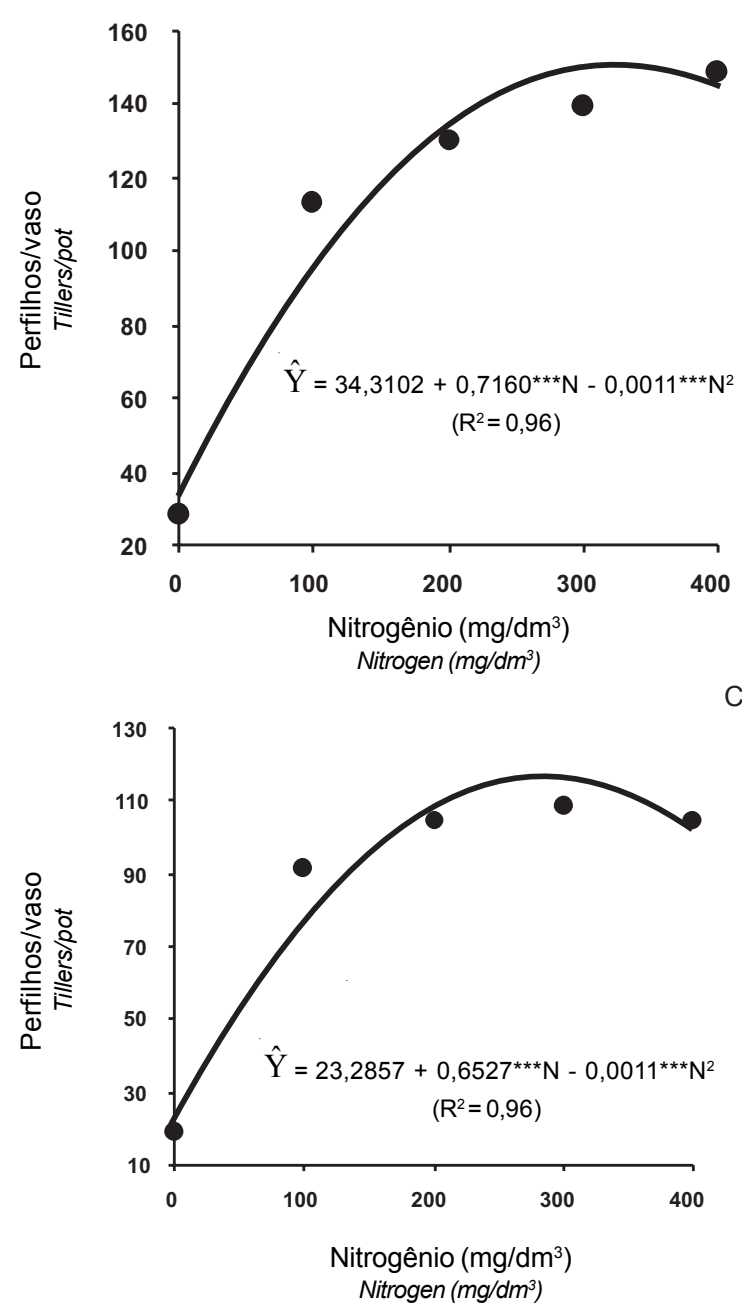

Figura 1 - Número total de perfilhos de capim-braquiária no primeiro corte (A) em função da combinação de doses de $\mathrm{N}$ e $\mathrm{S}$ e, no segundo e terceiro cortes (B e C), em função da adubação com doses de $\mathrm{N}$.

${ }^{* \star *}$ Significativo a $0,1 \%$.

Figure 1 - Total number of tillers of signalgrass at the first harvest (A) as related to the combinations between $N$ and $S$ rates and at the second and third harvests ( $B$ and $C$ ) as related to $N$ rates.

${ }^{* * *}$ Significant at $0.1 \%$ 
A importância do N na produção de perfilhos do capimbraquiária, como relatada no presente trabalho, está de acordo com o descrito por Santos (1997), Batista (2002), Lavres Jr. \& Monteiro (2003), Mattos \& Monteiro (2003) e Santos Jr. \& Monteiro (2003).

De acordo com Langer (1963), o perfilhamento é regulado principalmente por genótipo, florescimento, luz, temperatura, fotoperíodo, umidade, nutrição mineral e cortes. Assim, a disponibilidade de $\mathrm{N}$ no solo interfere no perfilhamento das plantas forrageiras, sendo o nutriente mais importante no número de perfilhos (Laude, 1972).

Alexandrino et al. (2005), estudando o crescimento e características químicas e morfogênicas do capim-marandu [Brachiaria brizantha (Hochst. ex A. Rich.) Stapf cv. Marandu] submetido a cortes e a doses de N, verificaram grande diferença de perfilhamento ao longo do tempo de rebrotação em relação ao suprimento de N, observando que as plantas não adubadas com $\mathrm{N}$ quase não perfilharam ao longo do tempo.

$\mathrm{Na}$ análise de variância, para o número total de folhas verdes expandidas do capim-braquiária, não se verificou significância para a interação doses de $\mathrm{N} \times$ doses de $\mathrm{S}$ aplicadas ao solo, nos três crescimentos das plantas. No entanto, foi verificada significância tanto para as doses de $\mathrm{N}$ como para as de $\mathrm{S}$ no primeiro crescimento e apenas para as doses de $\mathrm{N}$ no segundo e terceiro crescimentos. Em todos esses casos, ocorreu ajuste a modelo quadrático de regressão.

No primeiro crescimento, foi constatado efeito isolado das doses de $\mathrm{N}$ e $\mathrm{S}$ no aumento do número de folhas verdes expandidas, com máximas produções de 345 e 311 folhas por vaso, nas doses de $\mathrm{N}$ e S de 256 e $22 \mathrm{mg} / \mathrm{dm}^{3}$, respectivamente (Figuras $2 \mathrm{~A}$ e 3 ). Esses resultados reafirmam a importância desses dois nutrientes na recuperação do capim-braquiária, conforme os resultados de Rodrigues (2002) e Mattos \& Monteiro (2003).

Werner \& Monteiro (1988) mencionaram que as maiores respostas de plantas forrageiras ao $\mathrm{S}$ têm ocorrido em solos arenosos com baixos teores de matéria orgânica e que pastagem exclusiva de gramíneas não adubadas com $\mathrm{N}$ e $\mathrm{P}$ mostram pouca ou nenhuma resposta ao S. No presente trabalho, o teor de matéria orgânica é considerado expressivo para o tipo de solo estudado (Neossolo Quartzarênico), no entanto, foi possível obter resposta à adubação com $\mathrm{S}$ no primeiro crescimento da gramínea.

As produções máximas de folhas no segundo e terceiro crescimentos foram de 410 e 372 folhas por vaso nas doses de $\mathrm{N}$ de 300 e $285 \mathrm{mg} / \mathrm{dm}^{3}$, respectivamente. Constatou-se, no tratamento que não recebeu $\mathrm{N}$, que a produção total de folhas representou $43 ; 22$ e 15\% das máximas obtidas,

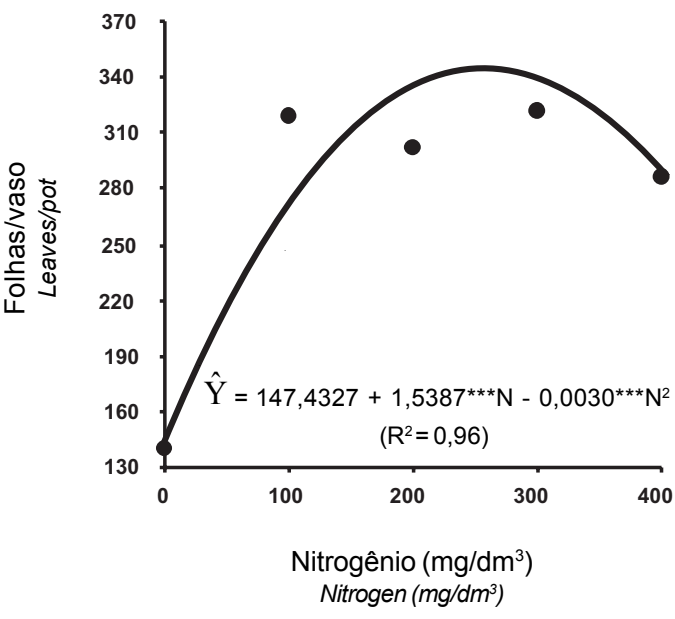

A
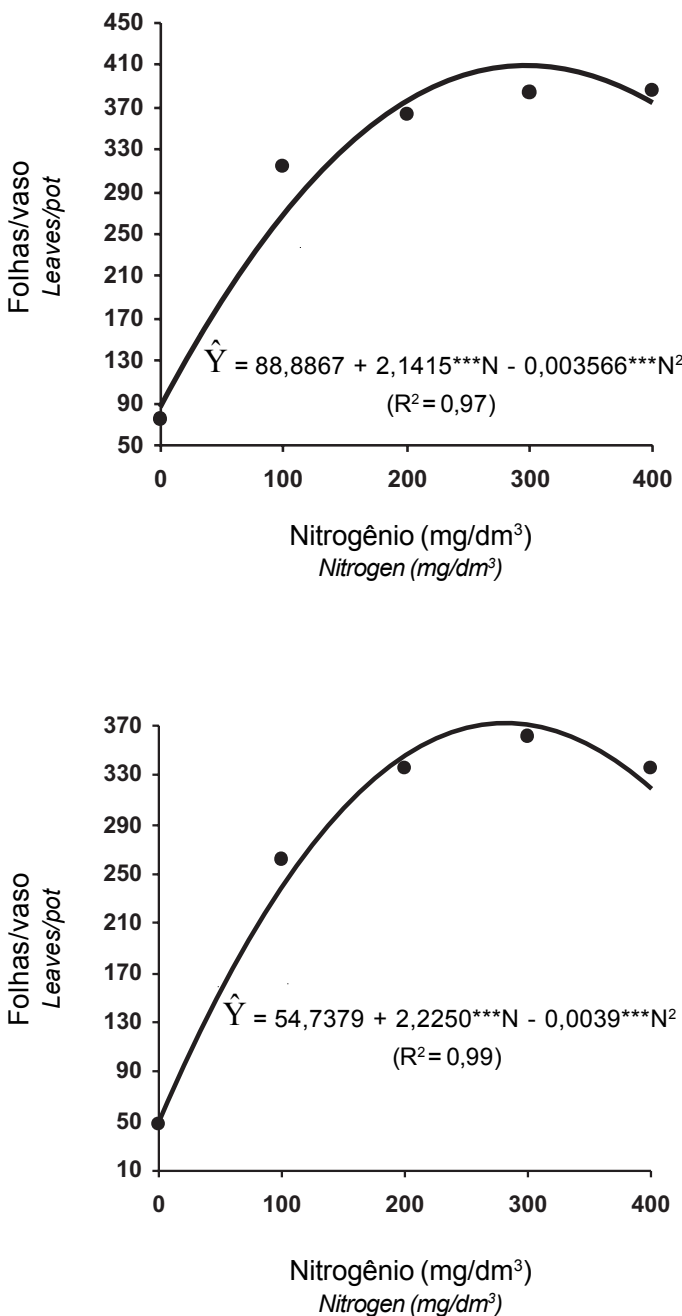

Figura 2 - Número total de folhas do capim-braquiária, no primeiro (A), segundo (B) e terceiro cortes (C), em função da adubação com doses de $\mathrm{N}$

*** Significativo a $0,1 \%$.

Figure 2 - Total number of leaves of signalgrass, at the first (A), second $(B)$ and third $(C)$ harvests as related to $N$ rates.

*** Significant at $0.1 \%$ 




Figura 3 - Número total de folhas do capim-braquiária no primeiro corte, em função da adubação com doses de S.

*** Significativo a $0,1 \%$.

Figure 3 - Total number of leaves of signalgrass at the first harvest as related to $S$ rates.

*** Significant at $0.1 \%$.

respectivamente, em cada um dos três crescimentos do capim-braquiária (Figuras 2A, 2B e 2C).

Esses resultados indicam a importância da adubação nitrogenada para a recuperação da gramínea, uma vez que o número de folhas está relacionado à produção de perfilhos, que, por sua vez, é um dos grandes responsáveis pela persistência da pastagem.

$\mathrm{O}$ aumento no número de folhas verificado com o incremento da adubação é importante para a recuperação da gramínea, tendo em vista que as folhas são órgãos fotossintetizantes onde é capturada e utilizada a energia luminosa para as reações químicas vitais à planta (Taiz \& Zeiger, 2004). Por outro lado, o número e o tamanho de folhas são componentes importantes para o índice de área foliar, sendo a área foliar a principal responsável pela interceptação de luz (Chapman \& Lamaire, 1993).

Esses resultados estão de acordo com os obtidos por Ruggieri et al. (1994), que observaram que o incremento das doses de $\mathrm{N}$ proporcionou aumento no número de folhas do capim-marandu em todos os cortes realizados, mostrando a importância desse nutriente para a produção de gramíneas forrageiras.

Um estudo com capim-marandu realizado por Schiavuzzo et al. (1999), avaliando respostas a doses de $\mathrm{N}$, também demonstrou que a produção de folhas verdes expandidas no primeiro crescimento foi influenciada pelo fornecimento do nutriente em solução nutritiva.

Lavres Jr. (2001), desenvolvendo trabalho com combinações de doses de $\mathrm{N}$ e K em capim-mombaça (Panicum maximum Jacq. cv Mombaça), constatou que a produção total de folhas em função do fornecimento dos nutrientes em solução nutritiva apresentou o máximo número no primeiro crescimento, na dose de $\mathrm{N}$ de $324 \mathrm{mg} / \mathrm{L}$, não sendo significativa a interação doses de $\mathrm{N} \times$ doses de $\mathrm{K}$.

Batista (2002), em estudo de superfície de resposta da produção de folhas verdes expandidas pelo capim-marandu, demonstrou que as máximas produções foram obtidas nas doses de $\mathrm{N}$ de 358 e $379 \mathrm{mg} / \mathrm{L}$, respectivamente, para o primeiro e segundo crescimentos.

Lavres Jr. et al. (2004), considerando os componentes de produção e morfogênese do capim-aruana (Panicum maximum Jacq. cv. Aruana) em resposta ao N, verificaram que a taxa de aparecimento de folhas verdes expandidas foi influenciada pelas doses de $\mathrm{N}$, ajustando-se ao modelo quadrático de regressão.

A produção de massa seca das lâminas foliares do capim-braquiária apresentou comportamento diferenciado do primeiro para o segundo e terceiro cortes das plantas. A interação doses de $\mathrm{N} \times$ doses de $\mathrm{S}$ foi significativa para a produção de lâminas foliares por ocasião do primeiro crescimento, ajustando-se ao modelo polinomial de regressão no estudo de superfície de resposta. No entanto, para o segundo e terceiro cortes, foi verificada significância apenas para as doses de N, com ajuste dos resultados ao modelo quadrático de regressão.

No estudo da superfície de resposta para a produção de lâminas foliares, no primeiro crescimento, observa-se que a aplicação conjunta de doses de $\mathrm{N}$ e $\mathrm{S}$ contribuiu positivamente com a produção de massa seca das lâminas foliares e que a máxima produção foi obtida nas doses 303 e $29 \mathrm{mg} / \mathrm{dm}^{3}$ (relação N:S de 10:1), respectivamente (Figura 4A). Essa dose de $\mathrm{S}$ está próxima daquela encontrada por Monteiro \& Carriel (1987), que indicaram a necessidade de aplicação de $\mathrm{S}$ de 30 a $40 \mathrm{~kg} / \mathrm{ha}$ para o capim-colonião.

Para o segundo e terceiro cortes, o $\mathrm{N}$ teve efeito isolado e desempenhou papel fundamental na produção das lâminas foliares do capim-braquiária. As doses de $\mathrm{N}$ de 371 e $305 \mathrm{mg} / \mathrm{dm}^{3}$, respectivamente, foram responsáveis pelas máximas produções de massa seca das lâminas foliares (Figuras 4B e 4C). Esse efeito isolado do $\mathrm{N}$ possivelmente não dependeu de novas aplicações de $S$, em razão de sua reserva acumulada no primeiro crescimento da gramínea ter sido suficiente para atender suas exigências nutricionais.

De acordo com Taiz \& Zeiger (2004), o crescimento vegetal pode ser analisado em termos de número de células ou tamanho geral (massa seca). O crescimento total da planta pode ser considerado como a soma dos padrões locais de expansão celular. Essas medições são realizadas por meio da produção de massa seca. Assim, foi verificado que, de forma similar ao número de folhas, a adubação com 


$$
\begin{aligned}
& \hat{Y}=2,9472+0,0760^{* \star *} N-0,000145^{* \star *} N^{2}+0,00041^{\star \star} N S+0,1869^{* *} S- \\
& 0,0054^{* \star} S^{2}\left(R^{2}=0,86\right)
\end{aligned}
$$

A

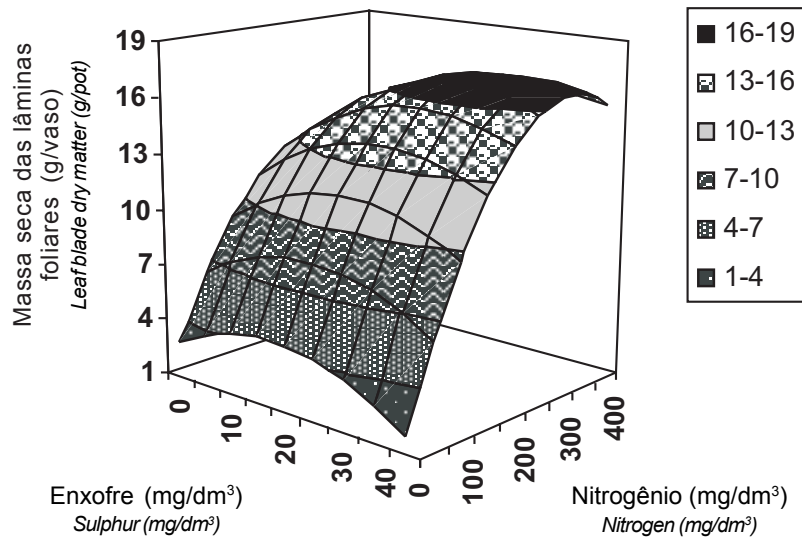

B

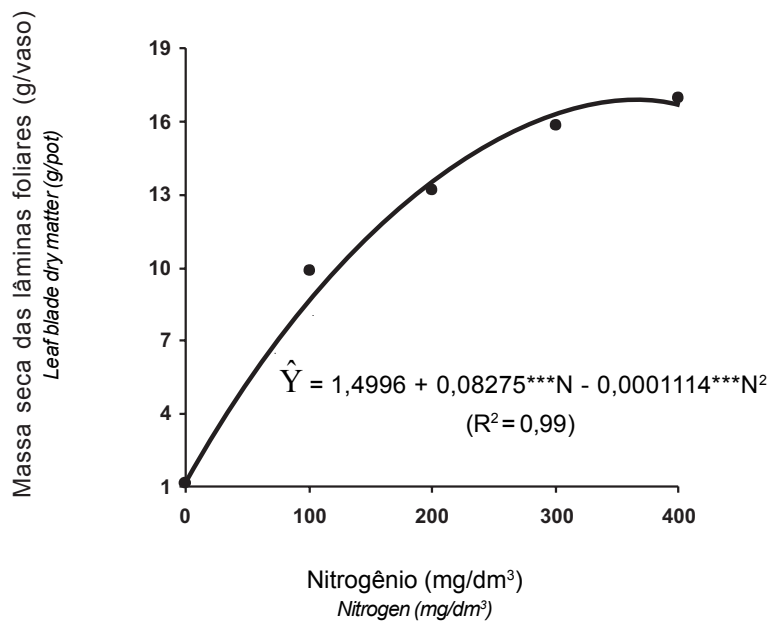

C



Figura 4 - Massa seca das lâminas foliares do capim-braquiária no primeiro corte $(A)$, em função da combinação de doses de $\mathrm{N}$ e $\mathrm{S}$, e no segundo e terceiro cortes (B e C), em função da adubação com doses de $\mathrm{N}$.

${ }^{* * *}$ Significativo a $0,1 \%$.

Figure 4 - $\quad$ Leaf blade dry matter of signalgrass, at the first harvest (A) as related to the combinations between $N$ and $S$ rates and at the second and third harvests ( $B$ and $C$ ) as related to $N$ rates.

${ }^{* * *}$ Significant at $0.1 \%$
$\mathrm{N}$ e S favoreceu o aumento da massa das lâminas foliares, indicando que o incremento na adubação nitrogenada contribuiu efetivamente no aumento da produção e conseqüentemente na recuperação do capim-braquiária.

Para a produção de massa seca dos colmos mais bainhas do capim-braquiária, o comportamento foi semelhante ao da produção de lâminas foliares, com interação significativa doses de $\mathrm{N} \times$ doses de $\mathrm{S}$ apenas para o primeiro corte, para o qual os resultados mostraram ajuste ao modelo polinomial de regressão. No segundo e terceiro crescimentos, verificou-se significância apenas para as doses de N, com ajuste dos resultados ao modelo quadrático de regressão.

No primeiro corte (Figura 5A), observou-se que as doses combinadas de $\mathrm{N}$ e de $\mathrm{S}$ para a máxima produção de colmos mais bainhas foram de 308 e de $31 \mathrm{mg} / \mathrm{dm}^{3}$, respectivamente. As máximas produções ocorreram em relação $\mathrm{N}$ :S na adubação de 10:1, o que é similar ao encontrado para a produção de massa seca das lâminas foliares.

No segundo e terceiro cortes, as doses de N responsáveis pelas máximas produções de colmos mais bainhas foram de 364 e $292 \mathrm{mg} / \mathrm{dm}^{3}$ (Figuras 5B e 5C). A produção de massa seca dos colmos mais bainhas seguiu o mesmo comportamento da produção de massa seca das lâminas foliares nos três cortes, indicando que o fornecimento de $\mathrm{N}$ estimula não só o aparecimento e desenvolvimento das folhas, como também o desenvolvimento dos colmos do capim-braquiária.

Esses resultados estão de acordo com os relatados por Sarmento (2005) que observou aumento na massa seca dos colmos mais bainhas do Panicum maximum Jacq. (acesso BRA-006998) com a adubação nitrogenada.

A relação folha:colmo é uma variável de grande importância para a nutrição mineral e para o manejo das plantas forrageiras. Alta relação folha:colmo representa forragem de elevado teor de proteína, digestibilidade e consumo, capaz de atender às exigências nutricionais dos ruminantes, garantindo maior ganho de peso ou produção de leite pelos animais (Wilson, 1982). Do mesmo modo, a alta relação folha:colmo confere à gramínea melhor adaptação ao pastejo ou tolerância ao corte, por apresentar um momento fenológico em que os meristemas apicais se apresentam mais próximos ao solo e, portanto, menos vulneráveis à destruição pelo corte animal ou máquina (Pinto et al., 1994).

Nos três cortes do capim-braquiária, a relação folha:colmo apresentou comportamento diferenciado. No primeiro e terceiro cortes, a análise de variância revelou significância somente para as doses de N, com ajuste dos resultados ao modelo quadrático de regressão. No segundo corte, essa relação mostrou significância para a interação doses de $\mathrm{N} \times$ doses de $\mathrm{S}$. 
$\hat{\mathrm{Y}}=1,4467+0,0825^{\star \star *} \mathrm{~N}-0,0002^{\star \star *} \mathrm{~N}^{2}+0,0005^{*} \mathrm{NS}+0,1998^{\star} \mathrm{S}-$ $0,0055^{\star} S^{2} \quad\left(R^{2}=0,76\right)$



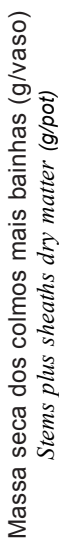

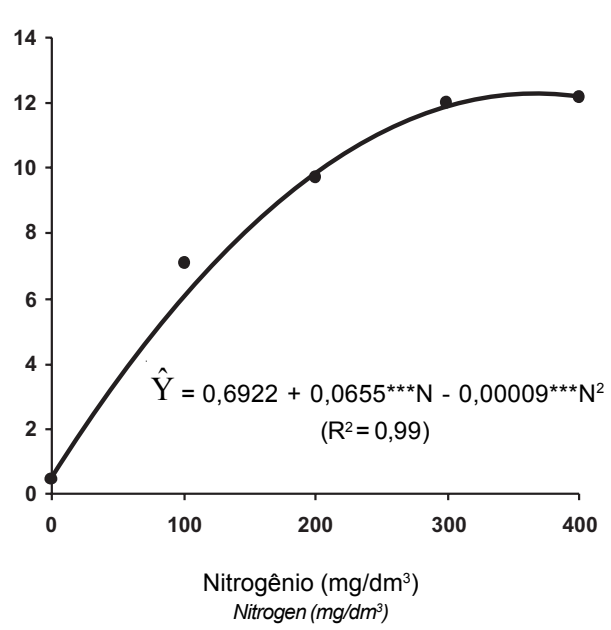

B

C
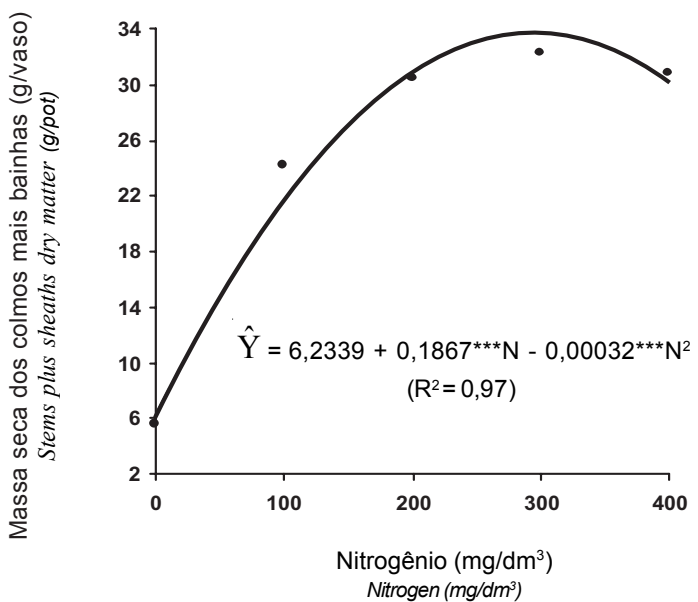

Figura 5 - Massa seca dos colmos mais bainhas do capim-braquiária no primeiro corte $(A)$, em função da combinação de doses de $\mathrm{N}$ e $\mathrm{S}$, e no segundo e terceiro cortes (B e C), em função da adubação com doses de $\mathrm{N}$.

${ }^{*}$ e ${ }^{* *}$ Significativo a 5 e $0,1 \%$.

Figure 5 - Stems plus sheaths dry matter of signalgrass at the first harvest $(A)$ as related to the combinations between $N$ and $S$ rates and at the second and third harvests (B and $C$ ) as related to the $N$ rates.

${ }^{*}$ and ${ }^{* * *}$ Significant at 5 and $0.1 \%$.


Figura 6 - Relação folha:colmo no segundo corte (B), em função da combinação de doses de $\mathrm{N}$ e $\mathrm{S}$, e no primeiro e terceiro cortes ( $\mathrm{A}$ e $\mathrm{C}$ ), em função da adubação com doses de $\mathrm{N}$.

${ }^{*} e^{* * *}$ Significativo a 5 e $0,1 \%$.

Figure 6 - Leaf:stem ratio of signalgrass, at the second harvest (B) as related to the combinations between $N$ and $S$ rates, and at the first and third harvests ( $A$ and $C$ ) as related to the $N$ rates.

${ }^{*}$ and ${ }^{* * *}$ Significant at 5 and $0.1 \%$. 
No primeiro corte verificou-se que a dose de $\mathrm{N}$ para a mínima relação folha:colmo foi de $293 \mathrm{mg} / \mathrm{dm}^{3}$, com valor da relação de 0,96 (Figura 6A).

No segundo corte, a relação folha:colmo foi influenciada pelas doses conjuntas de $\mathrm{N}$ e de $\mathrm{S}$, ajustando-se ao modelo polinomial de regressão (Figura 6B). De acordo com a superfície de resposta, a mínima relação folha:colmo foi de 1,00 , ocorrendo na dose de $\mathrm{N}$ de $287 \mathrm{mg} / \mathrm{dm}^{3}$ associada à dose de $\mathrm{S}$ de $17 \mathrm{mg} / \mathrm{dm}^{3}$ (relação N:S na adubação de 17:1).

Esses decréscimos na relação folha:colmo observados no primeiro e segundo cortes estão de acordo com os resultados apresentados por Pinto et al. (1994) e Lavres Jr. et al. (2004), para gramíneas forrageiras. Assim, o incremento na adubação, principalmente com $\mathrm{N}$, aumenta mais a produção de colmos mais bainhas que a de folhas das gramíneas forrageiras, que, conseqüentemente, diminui a relação folha:colmo. O limite crítico dessa relação é considerado igual a 1,00 e esse nível crítico considera a quantidade e a qualidade da forragem produzida (Pinto et al., 1994; Andrade, 1997).

No terceiro crescimento, a resposta da relação folha:colmo à adubação nitrogenada foi bem diferente dos outros dois crescimentos, com ajuste ao modelo quadrático ascendente de regressão. A maior relação folha:colmo foi obtida na dose de $\mathrm{N}$ de $287 \mathrm{mg} / \mathrm{dm}^{3}$, com valor de relação de 0,54. Quando o N não foi aplicado, a relação folha: colmo foi de 0,28 (Figura 6C).

Uma característica importante a ser considerada no presente trabalho é que os dois primeiros cortes do capimbraquiária foram realizados à altura de $5 \mathrm{~cm}$ do colo das plantas, enquanto o terceiro foi realizado rente ao colo das plantas e, desse modo, maior massa de colmos foi coletada, incluindo-se mesmo aqueles remanescentes dos cortes anteriores que foram então somados ao terceiro corte. Isso, provavelmente, contribuiu para a baixa relação folha:colmo no terceiro corte, relação esta que ficou abaixo do nível crítico.

De acordo com Martha Jr. et al. (2004), a relação folha:colmo do capim-tanzânia (Panicum maximum Jacq. cv. Tanzânia 1) aumentou linearmente com o tempo na primavera, depois da adubação nitrogenada e quando o pastejo foi intenso (baixo resíduo pós-pastejo). Esse baixo resíduo póspastejo, que teria sido simulado pelos cortes a $5 \mathrm{~cm}$ do colo da planta, é o responsável pela capacidade de rebrota.

\section{Conclusões}

As doses combinadas de $\mathrm{N}$ e $\mathrm{S}$ são determinantes para o número de perfilhos, produção de massa seca das lâminas foliares e dos colmos mais bainhas, no primeiro corte e para a relação folha:colmo no segundo crescimento do capim-braquiária.

A adubação com $\mathrm{N}$ tem efeito isolado para o número de perfilhos, produção de massa seca das lâminas foliares e dos colmos mais bainhas no segundo e no terceiro cortes do capim-braquiária.

O número de folhas do capim-braquiária é influenciado pelas doses de $\mathrm{N}$ e $\mathrm{S}$ de forma isolada, no primeiro corte, e pelas doses de $\mathrm{N}$, no segundo e terceiro cortes.

As relações entre as doses de $\mathrm{N}$ e as de $\mathrm{S}$ para obtenção das máximas produções de massa seca, de maneira geral, estão em torno de 10:1.

\section{Literatura Citada}

ALEXANDRINO, E.; NASCIMENTO JR., D.; REGAZZI, A.J. et al. Características morfogênicas e estruturais da Brachiaria brizantha cv. Marandu submetida a diferentes doses de nitrogênio e frequências de corte. Acta Scientiarum, v.27, n.1, p.7-14, 2005

ANDRADE, A.C. Produtividade e valor nutritivo do capimelefante (Pennisetum purpureum Schum. cv. Napier) sob diferentes doses de nitrogênio e potássio. Viçosa, MG: Universidade Federal de Viçosa, 1997. 52p. Dissertação (Mestrado em Zootecnia) - Universidade Federal de Viçosa, 1997.

BATISTA, K. Respostas do capim-marandu a combinações de doses de nitrogênio e enxofre. Piracicaba: Escola Superior de Agricultura "Luiz de Queiroz", 2002. 91p. Dissertação (Mestrado em Solos e Nutrição de Plantas) - Escola Superior de Agricultura "Luiz de Queiroz", 2002.

BONFIM-SILVA, E.M. Níveis críticos de fósforo para Brachiaria brizantha (Hochst ex A. Rich.) Stapf. cv. Marandu em solos de referência de Pernambuco. Recife: Universidade Federal Rural de Pernambuco, 2002. 57p. Dissertação (Mestrado em Ciência do Solo) - Universidade Federal Rural de Pernambuco, 2002.

CHAPMAN, D.F.; LAMAIRE, G. Morphogenetic and structural determinants of plant regrowth after defoliation. In: INTERNATIONAL GRASSLAND CONGRESS, 17., 1993 , Palmerston North. Proceedings... Palmerston North: New Zealand Grassland Association, 1993. p.95-104.

FERREIRA, C.R.R.P.T.; VEGRO, C.L.R.; BORTOLETO, E.E. et al. Caracterização da pecuária bovina no Estado de São Paulo. Informações Econômicas, v.29, n.9, p.7-30, 1999.

LANGER, R.H.M. Tillering in herbage grasses. Herbage Abstracts, v.33, n.3, p.141-148, 1963.

LAUDE, H.M. External factors affecting tiller development. In: YOUnGNER, V.B.; McKELL, C.M. (Eds.) The biology and utilization of grasses. New York: Academic Press, 1972. p.146-154.

LAVRES JR., J. Combinações de doses de nitrogênio e de potássio para o capim-mombaça. Piracicaba: Escola Superior de Agricultura “ Luiz de Queiroz”, 2001. 103p. Dissertação (Mestrado em Solos e Nutrição de Plantas) - Escola Superior de Agricultura “Luiz de Queiroz”, 2001.

LAVRES JR., J.; MONTEIRO, F.A. Perfilhamento, área foliar e sistema radicular do capim-mombaça submetido a combinações de doses de nitrogênio e potássio. Revista Brasileira de Zootecnia, v.32, n.5, p.1068-1075, 2003.

LAVRES JR., J.; FERRAGINE, M.D.C.; GERDES, L. et al. Yield components and morphogenesis of Aruanagrass in response to nitrogen supply. Scientia Agricola, v.61, n.6, p.632-639, 2004 . 
LITTELL, R.C.; MOTT, G.O. Computer assisted design and analysis of response surface experiments in agronomy. Soil and Crop Society of Florida Proceedings, v.34, n.1, p.94-97, 1975.

MACEDO, M.C.M. Degradação de pastagens; conceitos e métodos de recuperação In: SUSTENTABILIDADE DA PECUÁRIA DE LEITE NO BRASIL, 1999, Juiz de Fora. Anais... Juiz de Fora: Sociedade Brasileira de Ciência do Solo, 1999. p.137-150.

MARTHA JR., G.B.; CORSI, M.; BARIONI, G.L. et al. Intensidade de desfolha e produção de forragem do capim-tanzânia irrigado na primavera e no verão. Pesquisa Agropecuária Brasileira, v.39, n.9, p.927-936, 2004.

MATTOS, W.T.; MONTEIRO, F.A. Produção e nutrição de capimbraquiária em função de doses de nitrogênio e enxofre. Boletim de Indústria Animal, v.60, n.1, p.1-10, 2003.

MONTEIRO, F.A.; CARRIEL, J.M. Aplicação de níveis de enxofre na forma de gesso para o cultivo de capim-colonião em dois solos arenosos do Estado de São Paulo. Boletim de Indústria Animal, v.44, n.2, p.335-347, 1987.

MYERS, R.K.; ROBBINS, G.B. Sustaining productive pastures in the tropics. 5. Maintaining productive sown grass pastures. Tropical Grasslands, v.25, n.2, p.104-110, 1991

PINTO, J.C., GOMIDE, J.A., MAESTRI, M. Produção de matéria seca e relação folha/caule de gramíneas forrageiras tropicais cultivadas em vaso, com duas doses de nitrogênio. Revista da Sociedade Brasileira de Zootecnia, v.23, n.3, p.313326, 1994.

RODRIGUES, R.C. Calcário, nitrogênio e enxofre para recuperação do capim-braquiária cultivado em solo proveniente de uma pastagem degradada. Piracicaba: Escola Superior de Agricultura "Luiz de Queiroz", 2002. 141p. Dissertação (Mestrado em Zootecnia) - Escola Superior de Agricultura "Luiz de Queiroz", 2002.

RUGGieri, A.C.; FAVORETTO, V.; MALheiros, E.B. Características de crescimento e produção de matéria seca da Brachiaria brizantha (Hochst) Stapf. cv. Marandu em função de níveis de nitrogênio e regimes de corte. Boletim de Indústria Animal, v.51, n.2, p.149-155, 1994.

SANTOS JR., J.G.; MONTEIRO, F.A. Nutrição de capim-marandu submetido a doses de nitrogênio e idade de crescimento. Boletim de Indústria Animal, v.60, n.2, p.139-146, 2003.
SANTOS, A.R. Diagnose nutricional e respostas do capimbraquiária submetido a doses de nitrogênio e enxofre. Piracicaba: Escola Superior de Agricultura "Luiz de Queiroz", 1997. 115p. Tese (Doutorado em Solos e Nutrição de Plantas) - Escola Superior de Agricultura "Luiz de Queiroz", 1997.

SARMENTO, P. Respostas agronômicas e morfológicas de Panicum maximum Jacq. (acesso BRA-006998), sob pastejo, à adubação nitrogenada. Jaboticabal: Universidade Estadual Paulista, 2005. 92p. Tese (Doutorado em Zootecnia) Universidade Estadual Paulista, 2005.

SCHIAVUZZO, P.F.; LAVRES JR., J.; MONTEIRO, F.A. Respostas fisiológicas do capim-marandu ao suprimento de nitrogênio. In: SIMPÓSIO DE INICIAÇÃO CIENTÍFICA DA UNIVERSIDADE DE SÃO PAULO, 7., 1999, Piracicaba. Anais... Piracicaba: Escola Superior de Agricultura "Luiz de Queiroz", 1999. p.313.

SOARES FILHO, C.V. Tratamento físico-químico, correção e adubação para recuperação de pastagens. In: ENCONTRO SOBRE RECUPERAÇÃO DE PASTAGENS, 1., 1993, Nova Odessa. Anais... Nova Odessa: Instituto de Zootecnia, 1993. p.79-117.

STATISTICAL ANALYSIS SYSTEM - SAS. The SAS system for windows. Release 6.08. Cary: 1996. 633p.

TAIZ, L.; ZEIGER, E. Fisiologia vegetal. Porto Alegre: Artmed, 2004. $719 \mathrm{p}$.

WERNER, J.C.; MONTEIRO, F.A. Respostas das pastagens à aplicação de S. In: SIMPÓSIO: ENXOFRE E MICRONUTRIENTES NA AGRICULTURA BRASILEIRA, 1998, Londrina. Anais... Londrina: EMBRAPA, CNPS; IAPAR, 1988. p.87-102.

WILSON, J.R. Environmental and nutritional factores affecting herbage quality. In: HACKER, J.B. (Ed.) Nutritional limits to production from pastures. Farnham Royal: CAB, 1982. p.111-131. 